\title{
Interpretation of the variability of peak flow rates in chronic bronchitis
}

\author{
E H RAMSDALE, M M MORRIS, F E HARGREAVE \\ From the Department of Medicine, St Joseph's Hospital and McMaster University, Hamilton, Ontario, Canada
}

\begin{abstract}
Increased diurnal variation of expiratory flow rates has been documented in patients with chronic bronchitis, but this could be secondary to the disease process of bronchitis rather than an associated disease - namely, asthma. Peak expiratory flow was measured twice daily before and after inhalation of $200 \mu \mathrm{g}$ salbutamol in 34 subjects with chronic bronchitis. The $\mathrm{FEV}_{1} \mathrm{ranged} \mathrm{from}$ $38 \%$ to $121 \%$ predicted. Diurnal variation (expressed as highest-lowest/highest $(\%)$ ) was increased in 18 subjects, all but three of whom had airflow obstruction and an increase in methacholine airway responsiveness. There was only a weak correlation between diurnal variation and airway responsiveness $(\mathrm{r}=-0.54)$ or the severity of the airflow obstruction. This finding, together with the occurrence of an increase in diurnal variation without an increase in methacholine airway responsiveness in three subjects, suggests that the increased diurnal variation in chronic bronchitis may have a different underlying mechanism from that in asthma.
\end{abstract}

An increased diurnal variability of peak expiratory flow (PEF) has been documented in patients with chronic bronchitis and airflow obstruction, ${ }^{1-3}$ but it is not clear whether this is due to associated asthma or is secondary to other factors, such as expectoration of sputum ${ }^{4}$ or magnification of normal variability due to the small diameter of the airways (Poiseuille's law). ${ }^{5}$ Interpretation of this increased variability is complicated by semantics, because asthma is defined functionally as "variable airflow obstruction." This definition, however, does not take into account the underlying pathology. In different diseases the events initiating the variability of airway narrowing may be different, even though the end result could be similar variability in airflow.

Recent studies have shown that mediator release occurs in asthmatic subjects in response to stimuli such as exercise ${ }^{7-9}$ or isocapnic hyperventilation of cold air, ${ }^{8}$ and increased "releasability" of mediator containing cells may be a fundamental abnormality in asthma. ${ }^{9-11}$ Bronchoconstriction in response to exercise or isocapnic hyperventilation therefore is likely to indicate the presence of asthma, although the absence

Address for reprint requests: Dr FE Hargreave, St Joseph's Hospital, Firestone Regional Chest and Allergy Unit, 50 Charlton Avenue East, Hamilton, Ontario, Canada L8N 4A6.

Accepted 21 April 1986 of bronchoconstriction cannot exclude the disease with certainty. In keeping with this hypothesis, we have reported that most patients with chronic bronchitis did not develop bronchoconstriction after isocapnic hyperventilation of cold air, ${ }^{12}$ unlike asthmatic patients with a similar level of airflow obstruction at the time of the test. ${ }^{13}$ We considered that an appreciable degree of asthma was unlikely to be present in subjects with chronic bronchitis and airflow obstruction if bronchoconstriction did not occur in response to hyperventilation.

We have therefore investigated diurnal variability of peak flow in subjects with chronic bronchitis, who were not considered to have clinical asthma and who did not develop bronchoconstriction in response to isocapnic hyperventilation. We included subjects with airflow obstruction ranging from mild to severe and some with no obstruction, in order to try to differentiate between effects caused by chronic bronchitis itself and those due to irreversible obstruction. We used a standardised method, ${ }^{14}$ and compared the variability with methacholine responsiveness because in asthmatic subjects the greater the increase in methacholine responsiveness the greater the diurnal variability.

\section{Methods}

SUBJECTS

The 34 subjects we describe in this paper were chosen 
from 43 we studied with a history of cigarette smoking and chronic bronchitis. ${ }^{6}$ All had had cough and sputum for three months for two consecutive years. None was considered to have asthma by the attending physician. Twenty seven were recruited from the Firestone Regional Chest and Allergy Unit at St Joseph's Hospital, and were selected by availability and willingness to enter the study. They were described in detail in a previous paper on bronchial responsiveness in chronic bronchitis. ${ }^{12}$ Sixteen additional subjects were recruited through a newspaper article seeking people who had smoked for more than 10 years and who had a smoker's cough. We excluded six of the original 27 from the present analysis because of findings during the study that were thought to be consistent with a possible diagnosis of asthma (three developed bronchoconstriction in response to hyperventilation of cold air, one had sputum eosinophilia, and two had improved spirometric performance by more than $15 \%$ with prednisone treatment), and one subject was unable to keep peak flow records. Two of the 16 additional subjects were excluded because they were found to develop bronchoconstriction in response to cold air challenge. Of the 34 remaining subjects, all but two had current cough and sputum, 28 were smokers, six were exsmokers, and none developed bronchoconstriction in response to hyperventilation of cold air. In eight subjects the $\mathrm{FEV}_{1}$ was less than $60 \%$ predicted; of these, five had no response to prednisone treatment, there was a medical contraindication to its use in one, and one had been taking prednisone since a hospital admission. The eighth was a volunteer to whom we could not give prednisone. All subjects gave written consent, and the study was approved by the hospital research committee.

\section{STUDY DESIGN}

The subjects attended the laboratory on three study days for the initial study, as described previously. ${ }^{12} \mathrm{~A}$ methacholine inhalation test, ${ }^{15}$ isocapnic hyperventilation of cold air, ${ }^{16}$ and spirometric tests before and after inhalation of salbutamol $200 \mu \mathrm{g}$ were performed on separate days. Prick skin tests with 16 common allergens were documented, blood was collected for a total eosinophil count, and morning sputum was examined for eosinophils.

When the initial study had been completed, the subjects measured PEF at home twice daily for one week, using a mini Wright peak flow meter. They recorded the best of three blows before and 15 minutes after inhaling salbutamol $200 \mu \mathrm{g}$ on awakening and in the afternoon between 1600 and 1800 hours. ${ }^{14}$ The salbutamol was taken by the subjects from a metered dose inhaler by the open mouth technique. $^{17}$
ANALYSIS

The subjects were divided into two groups. Seventeen subjects had no features which could be considered to 음 be associated with asthma (group 1). The remaining $\frac{\overline{\bar{S}}}{\sqrt{2}}$ 17 subjects (group 2) had some features that might be found in association with asthma, but all are non- ֻ specific and are often found in non-asthmatic sub- $\vec{\circ}$ jects: 10 subjects had positive skin test reactions to one or more common allergens, four showed an im- $\vec{\omega}$ provement in $\mathrm{FEV}_{1}$ by more than $15 \%$ after salbutamol, in two subjects the blood eosinophil count $\overrightarrow{\dot{x}}$ was slightly raised $\left(400-500 \times 10^{9} / 1\right)$ but without sputum eosinophilia, and one individual was taking prednisone following a hospital admission with pulmonary heart disease.

The diurnal variation of peak flow was calculated from the mean difference between the lowest (presalbutamol) and the highest (postsalbutamol), $\vec{\ominus}$ expressed as a percentage of the highest.

Linear regression analysis was used to investigate relationships between diurnal variation and

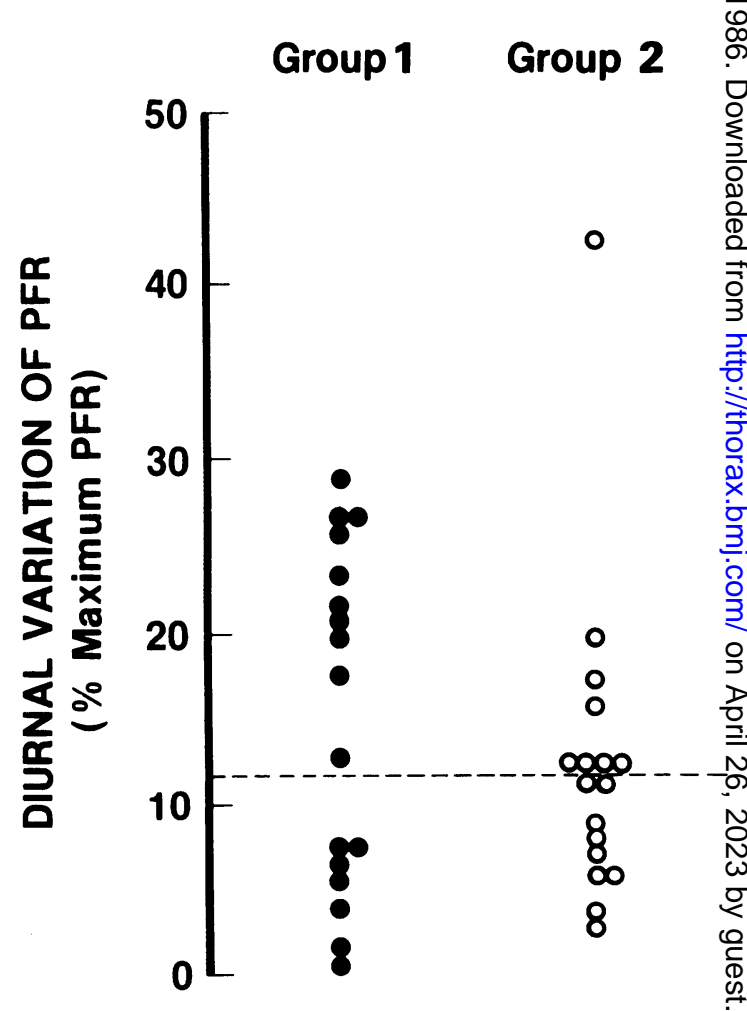

Fig 1 Diurnal variation (\% maximum) in 34 subjects with chronic bronchitis. -group 1; $\bigcirc-$ group 2 (for definition $\mathbb{D}$ of groups see under "Analysis"). The dotted line represents the upper boundary of the $95 \%$ confidence interval about the $\triangle$ mean of non-asthmatic subjects. ${ }^{14}$ PFR - peak expiratory flow. 
Summary of the subjects' characteristics and results

\begin{tabular}{|c|c|c|}
\hline & $\begin{array}{l}\text { Group } 1^{*} \\
(\text { mean }(S D))\end{array}$ & $\begin{array}{l}\text { Group 2* } \\
(\text { mean }(S D))\end{array}$ \\
\hline 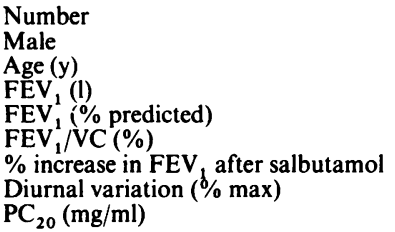 & $\begin{array}{l}17 \\
9 \\
9.2(12 \cdot 3) \\
53 \cdot 2(12 \cdot 3) \\
2 \cdot 31(0 \cdot 88) \\
80 \cdot 8(24 \cdot 0) \\
67 \cdot 6(15 \cdot 3) \\
6 \cdot 4(5 \cdot 5) \\
15 \cdot 0(9 \cdot 9) \\
5 \cdot 76(0 \cdot 14->64) \dagger\end{array}$ & $\begin{array}{l}17 \\
9 \\
90.5(12 \cdot 4) \\
50.5((1 \cdot 08) \\
2.45(29 \cdot 7) \\
82.0 \quad \\
64.4(16 \cdot 7) \\
10.9(15.9) \\
12.3(9 \cdot 2) \\
4.09(0.06->64) \dagger\end{array}$ \\
\hline
\end{tabular}

*See under "Analysis" for description of groups.

†Mean (range).

VC-vital capacity; $\mathrm{PC}_{20}$ - provocative concentration of methacholine producing a $20 \%$ fall in $\mathrm{FEV}_{1}$.

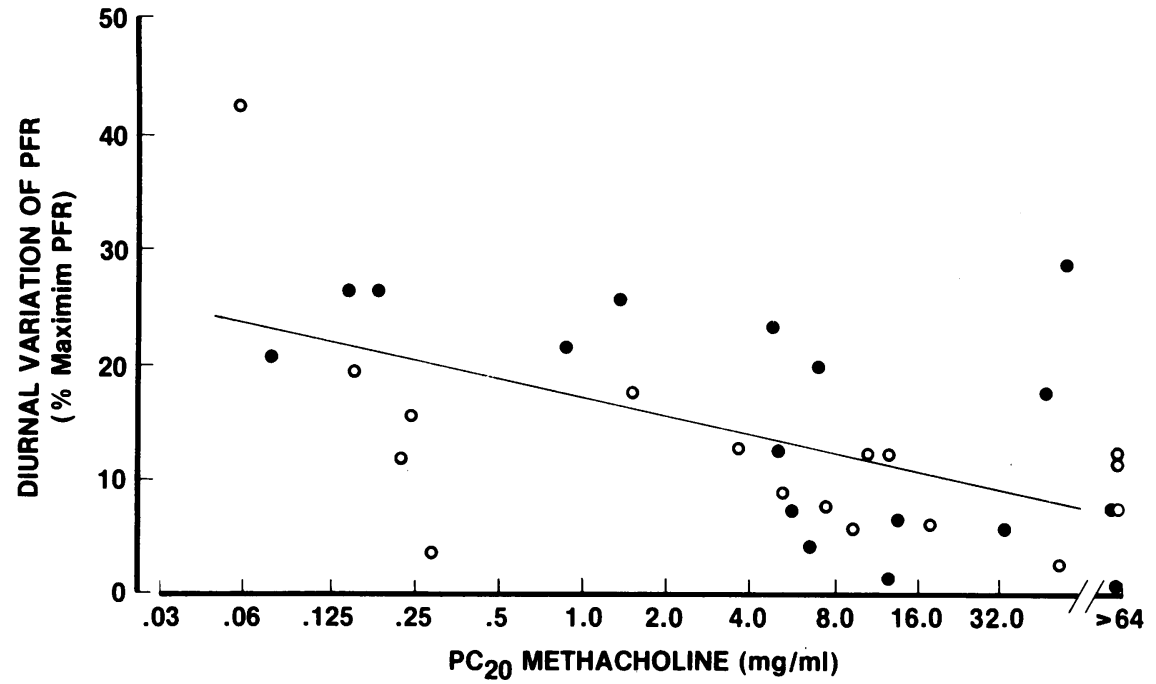

Fig 2 Relationship between diurnal variation (\% maximum) and bronchial responsiveness to methacholine $\left(P C_{20} \mathrm{mg} / \mathrm{ml}\right.$-provocative concentration producing a $20 \%$ fall in $\left.F E V_{1}\right)$. Symbols as in fig 1 . The solid line is the regression line; $r=-0.54, p<0.01$. PFR-peak expiratory flow.

methacholine responsiveness or airflow obstruction. Logarithmic transformation was used for all calculations of $\mathrm{PC}_{20}$ (the provocative concentration of methacholine that reduced $\mathrm{FEV}_{1}$ by $20 \%$ ).

\section{Results}

The variability of PEF was considered to be increased in 10 subjects in whom there were no features of asthma (group 1) and eight subjects in group 2 (fig 1). There were no differences in variability of PEF, airway responsiveness to methacholine, or severity of airflow obstruction between the two groups (table).

The variability was related to bronchial responsiveness to methacholine and to severity of airflow obstruction to investigate the likely mechanism of its increase. Although there was a correlation between variability of PEF and airway responsiveness to methacholine $\left(\mathrm{PC}_{20}\right)$, the relationship was not close $(r=-0.54, p<0.01$, fig 2$)$. Three subjects (two in group 1) had an increased variability of PEF despite normal airway responsiveness to methacholine. By contrast, nine subjects showed normal variability of PEF, but had an increase in methacholine responsiveness; seven of these, however, had only a borderline increase in responsiveness, with values of $\mathrm{PC}_{20}$ of $8-16 \mathrm{mg} / \mathrm{ml}$. There was a weak correlation between variability of PEF and severity of airflow obstruction when this was expressed as $\mathrm{FEV}_{1} / \mathrm{VC}(\mathrm{r}=-0.44, \mathrm{p}<0.05$; fig 3$)$ but not when it was expressed as $\mathrm{FEV}_{1}$ (\% predicted) $(\mathrm{r}=-0.24$, $\mathrm{p}>0 \cdot 1$ ) (fig 4). 


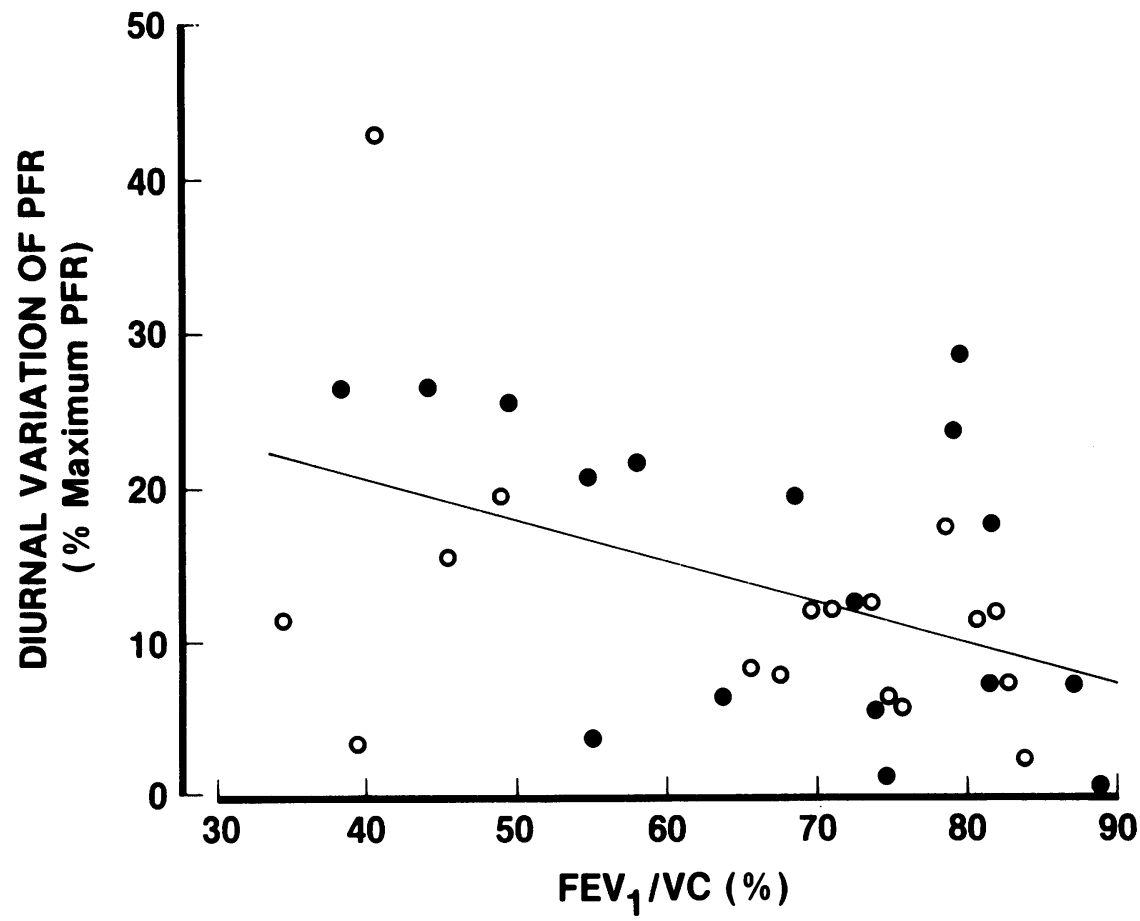

Fig 3 Relationship between diurnal variation (\% maximum) and the severity of airflow obstruction $\left(F E V_{1} / V C \%\right)$. Symbols as figure 1. The solid line is the regression line; $r=-0.44$, $p<0.05$. PFR - peak expiratory flow.

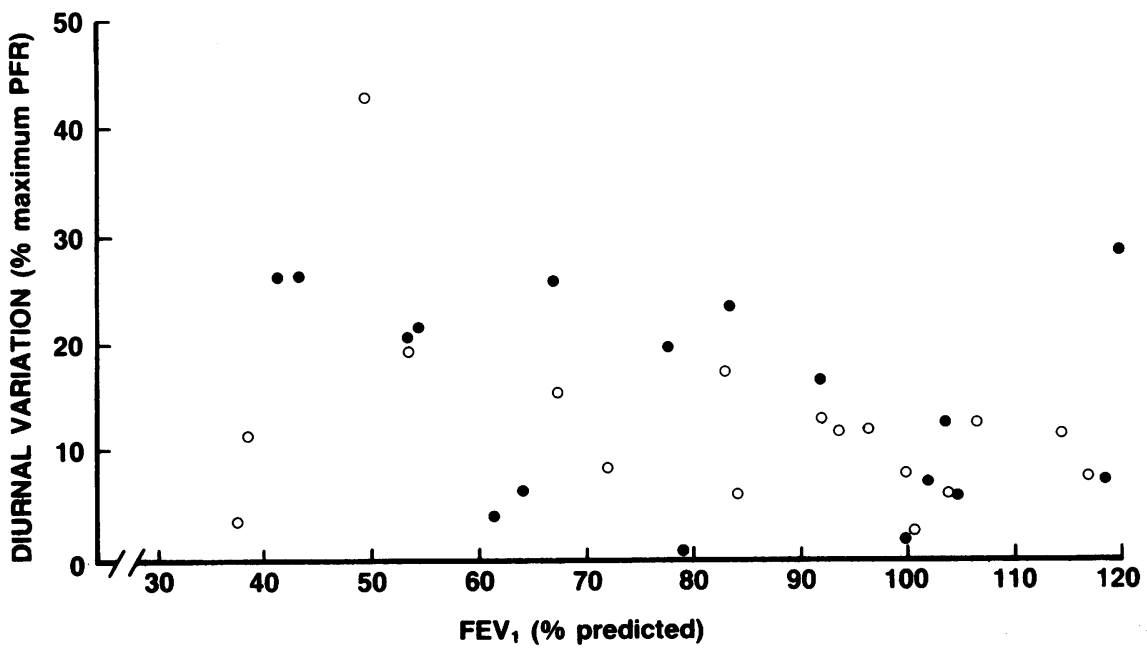

Fig 4 Relationship between diurnal variation ( $\%$ maximum) and FEV 1 (\% predicted). Symbols as in figure 1. PFR-peak expiratory flow. 


\section{Discussion}

This study has confirmed that increased variability of PEF occurs in many patients with chronic bronchitis and no other evidence of asthma. Although we found that there was a relationship between the increased variability of PEF and airway responsiveness to methacholine, unlike in asthmatic subjects ${ }^{14}$ the correlation was not strong. In addition, there was only a weak inverse correlation between variability of PEF and the severity of airflow obstruction if this was expressed as $\mathrm{FEV}_{1} / \mathrm{VC}(\%)$, and no significant relationship when expressed as $\mathrm{FEV}_{1} \%$ predicted. We believe that these findings are in keeping with the hypothesis that the mechanisms of the increase in variability are different in chronic bronchitis and in asthma, and that airflow obstruction does not account for the increased variability. Hence an increase in variability of PEF is not necessarily diagnostic of asthma if chronic bronchitis is present. The increased variability in some patients with no airflow obstruction and normal bronchial responsiveness to methacholine suggests that sputum production might be a contributory factor to the variability, but further studies are required to investigate this hypothesis.

On the basis of cosinor analysis, the diurnal variation of PEF in asthmatic subjects has been shown to be an exaggeration of the normal circadian rhythm. ${ }^{18}$ Thus the diurnal variability is not in itself abnormal. There are several factors that could increase the measured variability in those without asthma. Firstly, when the airways are narrowed small changes in diameter will result in greater changes in resistance (and hence flow rates) than in those with normal sized airways (Poiseuille's law). ${ }^{5}$ The measured variability would be increased, but in both cases the actual change in muscle tone would be the same. Secondly, when the measured flow rates are small, small absolute changes will produce large percentage changes. Thirdly, patients with chronic bronchitis produce sputum. Expectoration of sputum occurs most frequently in the morning, and this could decrease airways resistance. ${ }^{4}$ In addition, the viscoelastic properties of sputum show diurnal variation, ${ }^{19}$ and mucociliary clearance is decreased at night. ${ }^{20}$ The relationship between sputum and flow rates is complicated by a two phase interaction between air and liquid during forced breathing; consequently, although expectoration may decrease resistance, flow rates will not necessarily increase. ${ }^{421}$ Sputum production may, however, explain the increase in diurnal variation in those who had normal responsiveness to methacholine.

The method of calculation of the diurnal variation (cosinor analysis or highest - lowest (\%)), ${ }^{22}$ the timing of administration of bronchodilator, ${ }^{23}$ and the stability of the disease process ${ }^{24}$ can all affect the numerical results, and explain some of the conflicting results in the literature. The same method must be used if the results are to be comparable. The finding ${ }^{2}$ that the computed mean amplitude of the diurnal variation in chronic bronchitis was no different from that reported in normal subjects ${ }^{18}$ could be explained by the omission of bronchodilator. In the original comparison $^{18}$ between normal and asthmatic subjects, using cosinor analysis, asthmatics were receiving bronchodilator whereas the normal subjects were not, and there was no indication of the timing of the measurements in relation to bronchodilator administration. In addition, the asthmatic subjects were recovering from an exacerbation, which would increase their variability. In this study we have used a standardised method to control as many of the variables as possible, so that comparison across groups is possible. Twice daily measurement of PEF at home is practical and the standard administration of a bronchodilator to all groups enables the results from the bronchitic subjects to be compared with both those from asthmatic and normal subjects.

There is no direct way to confirm or exclude the presence of asthma or to determine whether all subjects with increased variability have the same underlying disease. Normally, when a diagnostic test is evaluated the diagnosis is verified against a "gold standard" in those with and without the disease and confirmation obtained that those with different but commonly confused disorders have a negative result. ${ }^{25}$ Since there is no "gold standard" for the diagnosis of asthma these steps cannot be followed. Indirect methods have to be used that are open to differing interpretations. In this study we suggest that the subjects are unlikely to have had additional asthma: half of the subjects had no other features suggestive of asthma (group 1) and would normally be considered to be definitely non-asthmatic. Moreover, there was no difference in the results between this group and the other subjects (group 2), in whom there were some features that could be associated with asthma. This suggests that these subjects were from the same population. In addition, none of the subjects developed bronchoconstriction in response to hyperventilation of cold air, which would be expected in all except those with mild asthma.

These findings suggest that greater diurnal variation of PEF in patients with chronic bronchitis than in normal subjects may not necessarily be due to associated asthma. Variability of airflow obstruction could result from more than one mechanism and the results suggest the need for caution in the interpretation of diagnostic tests for asthma when other disease processes are present. Further investigation may indicate an expected upper limit of variability of 
PEF in subjects with chronic bronchitis, and determine whether increases in excess of this are due to the additional presence of asthma.

This work was supported by a grant from the Medical Research Council of Canada. EHR is a fellow of the Ontario Ministry of Health. We thank Glaxo Canada Ltd, Toronto, for the supply of salbutamol and Mrs L Whitely for assistance in preparing the manuscript.

\section{References}

1 Connolly.CK. Diurnal rhythms in airway obstruction. Br J Dis Chest 1979;73:357-66.

2 Dawkins KD, Muers MF. Diurnal variation in airflow obstruction in chronic bronchitis. Thorax 1981;36:618-21.

3 Khoo KT, Connolly CK. A comparison of three methods of measuring broncholability in asthmatics, bronchitic cigarette smokers and normal subjects. Respiration 1984;45:219-24.

4 Cochrane GM, Webber BA, Clarke SW. Effects of sputum on pulmonary function. $\mathrm{Br}$ Med $J$ 1977; ii:1181-3.

5 Benson MK. Bronchial hyperreactivity. $\mathrm{Br} J$ Dis Chest 1975;69:227-39.

6 American Thoracic Society. Chronic bronchitis, asthma and pulmonary emphysema. A statement by the committee on diagnostic standards for non-tuberculous respiratory disease. Am Rev Respir Dis 1962;82:762-8.

7 Lee TH, Assoufi BK, Kay AB. The link between exercise, respiratory heat exchange, and the mast cell in bronchial asthma. Lancet 1983; i:520-2.

8 Holgate ST, Church MK, Cushley MJ, Robinson C, Mann JS, Howarth PH. Pharmacological modulation of airway calibre and mediator release in human models of bronchial asthma. In: Kay AB, Lichtenstein EM, Austin KF, eds. Asthma: physiology, immunopharmacology and treatment. London: Academic Press, 1984:391-413.

9 Neijens HJ, Raatgeep HC, Degenhart HJ, Kerrebijn KF. Release of histamine from leucocytes and its determinants in vitro in relation to bronchial responsiveness to inhaled histamine on exercise in vivo. Clin Allergy 1982;12:577-86.

10 Neijens HJ, Degenhart HJ, Raatgeep R, Kerrebijn KF. The correlation between increased reactivity of the bronchi and of mediator releasing cells in asthma. Clin Allergy 1980;10:535-9.
11 Findlay SR, Lichtenstein LM. Basophil releasability in patients with asthma. Am Rev Respir Di. 1980;122:53-9.

12 Ramsdale EH, Morris MM, Roberts RS, Hargreave FE Bronchial responsiveness to methacholine in chroniक bronchitis: relationship to cold air responsiveness Thorax 1984;39:912-8.

13 Ramsdale EH, Roberts RS, Morris MM, Hargreave $\mathrm{FE}_{\vec{O}}^{-}$ Differences in responsiveness to hyperventilation and methacholine in asthma and chronic bronchitis. Thorax 1985;40:422-6.

14 Ryan G, Latimer KM, Dolovich J, Hargreave FE Bronchial responsiveness to histamine: relationship tó diurnal variation of peak flow rate, improvement after $\vec{\overrightarrow{ }}$ bronchodilator, and airway calibre. Thora $\overrightarrow{0}$ 1982;37:423-9.

15 Juniper EF, Frith PA, Dunnett C, Cockcroft DW Hargreave FE. Reproducibility and comparison of response to inhaled histamine and methacholine. Thorax 1978;33:705-10.

16 O'Byrne PM, Ryan G, Morris M, McCormack D, Jone NL, Morse JLC, Hargreave FE. Asthma induced by cold air and its relation to nonspecific bronchiat responsiveness to methacholine. Am Res Respir Diş 1982;125:281-5

17 Thomas P, Williams T, Reilly PA, Bradley D. Modifying delivery technique of fenoterol from a metered dosE inhaler. Ann Allergy 1984;52:279-81.

18 Hetzel MR, Clark TJH. Comparison of normal anछ্ঠু asthmatic circadian rhythms in peak expiratory flovg rate. Thorax 1980;35:732-8.

19 Puchelle E, da Costa de Moraes R, Zahm JM. Variations diurnes de la viscoelasticite des secretions bronchique? chez le bronchitique chronique. Biorheolog 1975;12:67-71.

20 Bateman JRM, Pavia D, Clarke SW. The retention of lung secretions during the night in normal subjects Clin Sci Mol Med 1978;55:523-7.

21 Clarke SW, Jones JG, Oliver DR. Resistance to two phase gas-liquid flow in airways. J Appl Physiot 1970;29:464-71.

22 Hetzel MR. The pulmonary clock. Thora: 1981;36:481-6.

23 Clark TJH, Hetzel MR. Diurnal variation of asthma. $B_{6}$ J Dis Chest 1977;71:87-92.

24 Turner-Warwick M. On observing patterns of airflow obstruction in chronic asthma. $\mathrm{Br} J$ Dis ChesE. 1977;71:73-86.

25 Sackett DL, Haynes RB, Tugwell P. Clinical eptdemiology: a basic science for clinical medicine. Boston: Little, Brown, 1985:291-4. 